\title{
Geographen in der Dritten Welt
}

Das Interesse an der Auseinandersetzung mit Problemen der Dritten Welt drückt sich im Vorlesungsangebot vieler Fachrichtungen und in Diskussionsrunden verschiedenster Kreise aus. Wenn ein Engagement auch begrüßenswert ist, stimmt doch der Umstand nachdenklich, wie viele Schweizer sich in der Rolle eines «Experten» sehen, obwohl fach-spezifische und in manchen Fällen auch regionsbezogene Kenntnisse unerläßlich für ein erfolgreiches Wirken sind, das auch rein praktische Belange beinhaltet. Zur Vertrautheit mit dem Arbeitsgebiet zählen nicht nur Kenntnisse der naturräumlichen Ausstattung, sondern auch das Verständnis für tradierte Normen, die das Zusammenleben in der Gemeinschaft regeln, sowie Sprachkenntnisse, die es erlauben, mit der Bevölkerung ins Gespräch zu kommen. Es mag sich nun die Frage stellen, ob es sinnvoll sei, die Zahl der Mitberater für Belange der Dritten Welt durch Geographen zu vergrößern. Vermittelt das Fach Geographie Grundlagen, die bei einem Einsatz in Entwicklungsländern von Belang sind? Zielsetzung dieses Themenheftes ist es, auf den Willen und die Berechtigung - zur Mitsprache der Geographen im Kreis der Sachverständigen hinzuweisen. In den folgenden Aufsätzen äußern sich Geographen und eine Ethnologin, die sich über Feldaufenthalte in der Dritten Welt ausweisen können und zum Teil Mitarbeiter der DEH sind oder als Projektbearbeiter tätig waren.

PD K. I. ITTEN widmet sich dem Basisproblem «Geographie und Entwicklungszusammenarbeit»; in einem zweiten Teil seines Artikels wendet er sich praktischen Aufgaben zu, die dem Geographischen Institut der Universität Zürich übertragen wurden: Überprüfung der Volkszählung in Jemen, Landnutzungskartierung als Grundlage eines Agrarzensus in Nepal, Wirkungsgeflecht der Brandrodungskultur in Liberia, operationelle Reisernteprognosen in Sri Lanka.

Zur Tätigkeit bei der Direktion für Entwicklungszusammenarbeit und humanitäre Hilfe (DEH) gibt der Aufsatz von Dr. H. ESCHER (Koordinator DEH Bangladesh) Auskunft. Er legt Grundsätze und Zielsetzungen des DEH dar und vermittelt anhand eines Projektablaufs Einblick in die Tätigkeit eines Experten. Der Projektbeschrieb betrifft die Müllereifachschule in Mysore (Indien); in diesem Bericht wird auch die Arbeit eines Sachbearbeiters in der DEHZentrale Bern erwähnt.

Im Vordergrund des Artikels von Dr. A. BISAZ stehen Überlegungen eines DEH-Koordinators. Der Autor hält Rückschau auf seinen dreijährigen Feldaufenthalt in Kamerun und im Tschad. Dabei zeigt er die Ausarbeitung von Basiselementen für ein Konzept auf und schildert Schwierigkeiten in der Projektrealisierung. Eindrücklich verweist er auf bestehende Beziehungsgefüge, die es zu berücksichtigen gilt, wenn das Entwicklungsprojekt langfristig Erfolg haben soll.

Dr. H.STEFFEN (Bundesamt für Statistik) war Teamleiter der Zensusüberprüfung von 1975 in Jemen. Im Kapitel über die Arbeiteremigration aus der Arabischen Republik Jemen in die Erdölstaaten der arabischen Halbinsel belegt er, daß bei der Auswanderung nicht Push-Faktoren das migrationsauslösende Moment darstellen, sondern vielmehr das Lohngefälle für den Wanderentscheid maßgebend ist.

Die Basler Ethnologin BARBARA LÜEM beleuchtet in ihrem Aufsatz die Fünfer-Symbolik der Tenggeresen in Ost-Java. Sie zeigt, daß noch heute kleine religiöse und kulturelle Einheiten bestehen, die neben dem Restvolk der Badui als letzte Vertreter der altjavanischen Kultur gelten. Wenn die Autorin auch nicht explizit darauf hinweist, so zeigt es sich doch, daß bei Planungsvorhaben dem regionalen Volksgut Rechnung zu tragen ist, will man nicht mit Modernisierungsbestrebungen ein Restvolk entwurzeln.

Die Zürcher Geographin MARGRIT WEGMANN gibt in ihrem engagierten Aufsatz «Das Mädchen von Kumaon» Hinweise auf die Gestaltung von Unterrichtsseinheiten, die Kinder für Probleme Gleichaltriger in Entwicklungsländern sensibilisieren sollen, haben doch unsere Schüler oft nur vage, wenn nicht falsche, Vorstellungen. Zum Fehlverständnis tragen nicht zuletzt Kinderbücher bei, die von Autoren ohne vertiefte Grundkenntnisse der Fremdkultur geschrieben worden sind.

Den Autoren ist zu danken, daß sie mit ihren Artikeln eine weitere Öffentlichkeit auf die Bereitschaft der Geographen zu einer sinnvollen Mitarbeit aufmerksam gemacht haben.

Dr. Albert Leemann. Professor am Geographischen Institut der Universität Zürich, Postfach, 8033 Zürich. 